\section{P24 CORRELATION BETWEEN SERUM AUTOANTIBODIES AND CLINICAL MANIFESTATIONS IN JSLE}

${ }^{1}$ Sara Ganhão, ${ }^{1}$ Francisca Aguiar, ${ }^{1}$ Mariana Rodrigues, 1,2Iva Brito. 'Young Adult and Pediatric Rheumatology Unit, Centro Hospitalar e Universitário do Hospital de São João, Porto; ${ }^{2}$ Faculty of Medicine, University of Porto, Porto, Portugal

10.1136/lupus-2020-eurolupus.72

Background Systemic Lupus Erythematosus (SLE) has a large clinical spectrum, ranging from mild to severe disease. Some studies have proven correlations between specific autoantibodies and particular clinical manifestations. The aim is to assess if there is any correlation between autoantibodies and clinical manifestations in our sample.

Methods Retrospective longitudinal study of juvenile-onset SLE patients evaluated in Pediatric Rheumatologic unit of a tertiary Hospital. All patients fulfilled both 2012 and 2019 EULAR/ACR classification criteria for SLE. Juvenileonset was defined as age at diagnosis $<18$ years. Demographics and clinical characteristics were collected. Statistical analysis was performed with qui-square test by SPSS ${ }^{\circledR}$ software. Results were considered statistically significant if $\mathrm{p}<0.05$.

Results 30 jSLE patients were included (90\%female) with median (min-max) age of $21(16-35)$ years old, with mean (SD) age of diagnosis of $15.8 \pm 2.1$. Mucocutaneous manifestations occurred in 25, articular involvement in 16, hematologic in 14 , renal in 12 , pulmonary in 1 , pleuropericardial in 2 and another 2 with thrombotic events. All were positive for antinuclear antibodies: 18 with speckled pattern, 11 homogeneous and 1 nucleolar. 11 jSLE were positive for antinucleosomal autoantibodies, 10 anti-SSA antibodies, 8 anti-histone, 7 anti-ribossomal $\mathrm{P}$ protein antibody, 4 anti-Sm, 4 anti-RNP, 4 Lupus anticoagulant, 3 had autoantibodies against $\beta 2$-glycoprotein I, 2 anti-cardiolipin and 2 anti-SSB antibodies. The presence of antinucleossomal $(\mathrm{p}=0.003)$ and anti-SSA $(\mathrm{p}=0.04)$ antibodies was significantly associated with articular involvement; anti-histone with renal manifestations $(p=0.005)$ and lupus anticoagulant in serosal involvement $(\mathrm{p}=0.02)$.

Conclusions Anti-histone antibodies have been linked to lupus nephritis disease activity. The other associations are not described in the literature. Sample size is a limitation and further studies in our population are required.

\section{P25 DISRUPTED PLACE CELL PROPERTIES IN THE HIPPOCAMPUS REPRESENT THE NEURAL SUBSTRATE FOR COGNITIVE IMPAIRMENT IN NEUROPSYCHIATRIC LUPUS}

Patricio T Huerta, Joshua J Strohl, Tomás S Huerta. Laboratory of Immune and Neural Networks, Feinstein Institutes for Medical Research, Northwell Health, New York, USA

10.1136/lupus-2020-eurolupus.73

Background A poorly understood facet of lupus is its neurological component, known as Neuropsychiatric Systemic Lupus Erythematosus (NPSLE). Patients with NPSLE display severe cognitive impairment, particularly in the spatial domain. We have studied a mouse model of NPSLE in which animals carry a lupus antibody (termed DNRAb) that binds DNA and the GluN2A and GluN2B subunits of the N-methyl-D aspartate receptor (NMDAR).
Methods Female mice (Balb/c, C57) are immunized with either a lupus-inducing antigen (DNRAb+) or a control antigen (DNRAb-). A month later, the blood-brain barrier is abrogated to allow antibody entry to the hippocampus. We investigate spatial cognition with the object-place memory (OPM) task and the neural substrate with tetrode recordings in the CA1 region of the hippocampus. Neural data are analyzed via spike sorting (Spike2) to reveal place cell properties of CA1 neurons, as well as power spectral densities of network oscillations (Matlab, Chronux).

Results A discrimination ratio reveals that DNRAb+ mice examine the moved object significantly less than controls during OPM, indicating impaired spatial memory. The neural data show abnormal place cell properties in DNRAb + mice, such as expanded place field size, reduced stability, and lower spatial information when compared to DNRAb- mice. Bayesian path reconstruction analysis reveals that DNRAb+ place cells have significantly higher error compared to the DNRAbgroup. Moreover, we find significantly altered co-modulation of theta-gamma oscillations when the mice examine the objects during OPM.

Conclusions Our studies reveal that the CA1 ensemble encodes critical aspects of the OPM task through place cell dynamics and theta-gamma coupling. The disruptions of these processes caused by DNRAbs may explain the abnormal spatial encoding that occurs in NPSLE. Our data offer a neural substrate for bioelectronic therapies aimed to alleviate NPSLE-related cognitive impairment.

Acknowledgments The studies are funded by grants from NIH (P01-AI102852, P01-AI073693) and DOD (2019 Impact Award) to PTH.

\section{P26 SERUM BAFF AND APRIL AS CANDIDATE BIOMARKERS IN SYSTEMIC LUPUS ERYTHEMATOSUS (SLE): A PROSPECTIVE FOLLOW-UP STUDY}

${ }^{1}$ Selma Sari, ${ }^{2}$ Suzan Cinar, ${ }^{3}$ Bahar Artim Esen, ${ }^{3}$ Ahmet Gül, ${ }^{3}$ Lale Öcal, ${ }^{2}$ Günnur Deniz, ${ }^{3}$ Murat Inanç. ${ }^{1}$ Dept. of Internal Medicine, Istanbul Faculty of Medicine, Istanbul University, Istanbul; ${ }^{2}$ Dept. of Immunology, Aziz Sancar Institute of Experimental Medicine, Istanbul University, Istanbul; ${ }^{3}$ Dept. of Internal Medicine, Division of Rheumatology, Istanbul Faculty of Medicine, Istanbul University, Istanbul, Turkey

\subsection{6/lupus-2020-eurolupus.74}

Background BAFF and APRIL are cytokines involved in B cell development and they take place in SLE pathogenesis. The aim of this study was to investigate the relationship between serum BAFF/APRIL levels with clinical features and disease activity in SLE patients.

Methods We included 79 patients with SLE (SLICC criteria) and 27 healthy controls into the study. Serum BAFF and APRIL levels were assessed by ELISA. In 19 patients with active disease, BAFF/APRIL levels were reassessed at least 6 months later and disease activity was evaluated by SLEDAI. New renal involvement was observed in 16 patients during the study and renal involvement was previously detected in 12 patients.

Results Although both BAFF (median 0.7 vs $0.41 \mathrm{ng} / \mathrm{ml}$ ) and APRIL (median 2.3 vs $1.05 \mathrm{ng} / \mathrm{ml}$ ) levels were higher in patients with SLE compared to the control group ( $\mathrm{p}$ $<0.001$ ), no correlation was found between BAFF/APRIL levels and SLEDAI scores. When patients were grouped according to disease activity as no activity (SLEDAI $=0$ ), low 